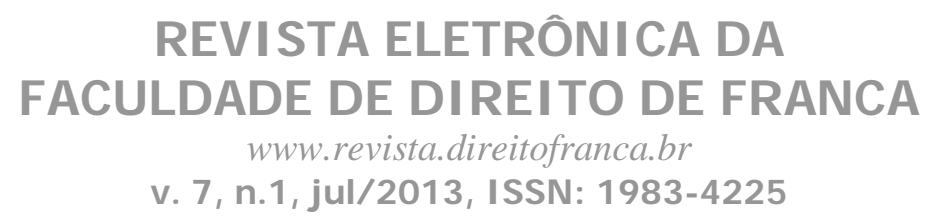

\title{
O PODER JUDICIÁRIO E A QUESTÃo AGRÁRIA: A IMPORTÂNCIA DA ATIVIDADE JURISDICIONAL PARA A CONCRETIZAÇÃO DAS POLÍTICAS PÚBLICAS DE REFORMA AGRÁRIA
}

Danilo Pereira Lima

http://buscatextual.cnpq.br/buscatextual/visualizacv.do?id=K4339502D6

Resumo: O trabalho vai analisar a dificuldade da administração pública para desempenhar suas funções e, ao mesmo tempo, demonstrar a importância da atividade jurisdicional para a democratização da atividade administrativa, nos casos que envolvem a realização das políticas públicas de reforma agrária, já que o Poder Judiciário deixou de ocupar uma posição secundária entre os outros dois poderes e passou a exercer um papel fundamental para a consolidação do regime democrático.

Palavras-chave: Judiciário; estamento; patrimonialismo; Constituição; Estado; administração; democracia.

The Judiciary and the agrarian issue: the importance of jurisdictional activity for the concretion of agrarian reform public policies

Abstract: This work will analyze the difficulty of the public administration to perform its functions and at the same time to demonstrate the importance of the jurisdictional activity for the democratization of the administrative activity in cases that involve the achievement of agrarian reform public policies; considering that the Judiciary has not occupied a secondary position among the other two powers and has started to perform a fundamental role for the consolidation of the democratic regime.

Keywords: Judiciary, estament, patrimonialism, Constitution, State, administration, democracy

\section{INTRODUÇÃO}

Após um longo período de intervenções militares, golpes de Estado e governos autoritários, a sociedade brasileira construiu uma Constituição democrática, dirigente e compromissória, voltada principalmente para o resgate das promessas da modernidade. Com isso, o velho modelo de Estado patrimonialista e estamental ${ }^{1}$ ficou em completa dissonância

\footnotetext{
${ }^{1}$ Cf. FAORO, Raymundo. Os donos do poder: formação do patronato político brasileiro. $3^{\circ}$ ed., São Paulo: Globo, 2001. O presente trabalho se inspira em Os donos do poder para melhor compreender todo esse fenômeno histórico de formação do Estado brasileiro. Em 1958, foi publicada a primeira edição de Os donos do poder, uma obra que se inspirou em Max Weber para compreender a formação do patronato político brasileiro e inaugurou uma outra forma de abordagem da formação do Brasil contemporâneo. Há nesta obra uma preocupação constante com a compreensão da totalidade da realidade brasileira, levando em consideração aspectos econômicos, políticos, sociais e jurídicos, que sempre estão inter-relacionados e, de alguma forma,
} 


\section{REVI STA ELETRÔNI CA DA FACULDADE DE DIREITO DE FRANCA \\ www.revista.direitofranca.br \\ v. 7, n.1, jul/ 2013, ISSN: 1983-4225}

com o Constitucionalismo Contemporâneo, ${ }^{2}$ transformando-se num grave obstáculo a realização do novo paradigma constitucional. Diferentemente da herança estatal lusitana, no paradigma do Estado Democrático de Direito a administração pública deve pautar sua atuação no sentido de construir uma sociedade livre, justa e solidária, por meio da incorporação, em seu ordenamento constitucional, de toda a temática de inclusão social. Dessa forma, com um ordenamento jurídico constituído nesses parâmetros, impõe-se a atividade administrativa um conteúdo de profunda transformação social, pois, de um modelo de Constituição formal, onde o Direito recebia apenas o papel de ordenação do Estado, passou-se ao Direito transformador da sociedade, no sentido de buscar a concretização da Democracia. Desse modo, para alcançar a realização desse novo paradigma estatal, é preciso enfrentar o Estado patrimonialista e estamental, que impede a concretização das políticas sociais estabelecidas pela Constituição. Diante dessa conjuntura, a administração pública não consegue desempenhar de maneira eficiente as políticas públicas determinadas pela Constituição, pois existe um abismo entre o Estado Democrático de Direito, estabelecido constitucionalmente, e o Estado patrimonialista e estamental, instituído no tempo do domínio português e ainda vigente no Brasil.

Diante de todas essas dificuldades enfrentadas pela administração pública, o Poder Judiciário aparece como um espaço institucional importante para a materialização dos direitos recentemente constitucionalizados. Frente ao deslocamento da esfera de tensão, até então apoiada nos procedimentos políticos, para os procedimentos judiciais, o Constitucionalismo Contemporâneo passou a exigir uma posição mais intervencionista do Poder Judiciário, como condição de possibilidade para superar a postura absenteísta do juiz como "boca inanimada da lei”, predominante no modelo liberal-individualista-normativista. ${ }^{3}$ Desse modo, o presente

contribuíram para a construção do Estado patrimonialista e estamental. Ao contrário de algumas interpretações marxistas, que entendem a formação do sistema político como simples manifestação dos interesses da classe dominante, Faoro chamou a atenção para a necessidade de compreender o sistema político a partir dele mesmo.

2 Cf. STRECK, Lenio Luiz. Verdade e Consenso. $4^{\circ}$ ed., São Paulo: Saraiva, 2011. Constitucionalismo Contemporâneo é a nova expressão cunhada pelo professor Lenio, para se referir ao constitucionalismo do segundo pós-guerra. Com efeito, a expressão neoconstitucionalismo chegou a um ponto de degradação semântica e desgaste significativo, que foi preciso estabelecer um sentido específico para esse novo modelo de constitucionalismo, que se afirma no contexto da "era de ouro" da democracia européia.

${ }^{3}$ Cf. VIANNA, Luiz Werneck; BURGOS, Marcelo Baumann; CARVALHO, Maria Alice Rezende de; MELO, Manuel Palacios Cunha. Corpo e Alma da Magistratura Brasileira, 3a ed., Rio de Janeiro: Editora Revan, 1997, p. 36. De acordo com Vianna, no início da formação do Estado Liberal de Direito, logo nos primeiros momentos da Revolução Francesa, o Poder Judiciário recebeu a tarefa de apenas funcionar como a "boca inanimada da lei”, já que lhe cabia a simples função de apenas aplicar as leis aprovadas pelos representantes do povo. Mais tarde, com a institucionalização da Revolução, a magistratura foi constituída como cargo burocrático do Estado, “concebendo-se o Judiciário como personagem sem rosto da ordem racional-legal do Estado de Direito, capaz de garantir previsibilidade à reprodução do mundo mercantil e certeza jurídica na administração do direito”. 


\section{REVI STA ELETRÔNI CA DA FACULDADE DE DI REITO DE FRANCA \\ www.revista.direitofranca.br \\ v. 7, n.1, jul/ 2013, ISSN: 1983-4225}

trabalho vai analisar o papel do Poder Judiciário para a concretização das políticas públicas de reforma agrária, ${ }^{4}$ a partir de uma posição substancialista, ${ }^{5}$ que procura se afastar completamente de qualquer tipo de discricionariedade judicial. Assim, para se distanciar dessa postura, que aposta no protagonismo judicial, o trabalho vai estabelecer uma crítica a indevida insistência do pensamento dogmático em continuar apoiando-se no positivismo jurídico, e que, conseqüentemente, tem colaborado no despreparo do Poder Judiciário para enfrentar as demandas constitucionais hodiernas, já que todas as transformações ocorridas na filosofia, a partir do giro ontológico-lingüístico, não foram devidamente recepcionadas pelo Direito.

Nesse sentido, frente a todos esses problemas, o trabalho vai analisar a dificuldade da administração pública para desempenhar suas funções ${ }^{6}$ e, ao mesmo tempo, demonstrar a importância da atividade jurisdicional para a democratização da atividade administrativa, nos casos que envolvem a realização das políticas públicas de reforma agrária. Evidentemente, a redefinição da função republicana do Poder Judiciário o colocou em uma posição proeminente para a concretização dos direitos sociais, ampliados pela Constituição Federal. Ao contrário do que ocorreu durante o Estado Liberal e o Welfare Estate, em que o Legislativo e o Executivo respectivamente tinham uma maior relevância nos debates constitucionais, no

\footnotetext{
${ }^{4}$ No Brasil, a concentração de terra transformou-se numa das facetas históricas do modelo de desenvolvimento econômico, responsável por uma violenta desigualdade social. Desse modo, a viabilização da reforma agrária atende aos objetivos republicanos de erradicação da pobreza e de redução substancial das desigualdades sociais. De fato, esta política pública é fundamental para a superação dos problemas sociais, pois aparece como alternativa ao alto índice de desemprego das grandes cidades e, ao mesmo tempo, permite a construção de um modelo de desenvolvimento voltado principalmente para produção de alimentos, pois no modelo atual, estabelecido há vários séculos, ainda predominam grandes propriedades monocultoras, trabalho degradante e a produção de matérias-primas voltadas essencialmente para o mercado externo.

${ }^{5}$ Cf. CAPPELLETTI, Mauro. Juízes Legisladores? Porto Alegre: Editor Sergio Antonio Fabris, 1993, p. 42. Em sentido oposto a posição sustentada neste trabalho, o professor Mauro Cappelletti afirma que, "é manifesto o caráter acentuadamente criativo da atividade judiciária e de atuação da legislação e dos direitos sociais. Deve reiterar-se, é certo, que a diferença em relação ao papel mais tradicional dos juízes é apenas de grau e não de conteúdo: mais uma vez impõe-se repetir que, em alguma medida, toda interpretação é criativa, e que sempre se mostra inevitável um mínimo de discricionariedade na atividade jurisdicional. Mas, obviamente, nessas novas áreas abertas à atividade dos juízes haverá, em regra, espaço para mais elevado grau de discricionariedade e, assim, de criatividade, pela simples razão de que quanto mais vaga a lei e mais imprecisos os elementos do direito, mais amplo se torna também o espaço deixado à discricionariedade nas decisões judiciárias”.

${ }^{6}$ Cf. HOBSBAWM, Eric. Mundos do trabalho, $5^{\circ}$ ed., Rio de Janeiro: Paz e Terra, 2000, p. 414 e 415 . Diante da imobilidade do Estado brasileiro para efetivar a reforma agrária constitucional, os trabalhadores rurais semterra se organizam em mobilizações e ocupações pacíficas, com o intuito de pressionar a administração pública a realizar as políticas públicas de reforma agrária. Segundo Eric Hobsbawm, “[...] o que os 'pobres’ fazem tem importância. Mais do que nunca, eles precisam não só de uma estratégia de pressões efetivas, mas de planos de ação - e de organismos capazes de executar estes planos. Eles não estão martelando de fora do sistema, mas de dentro, com o potencial de transformá-lo”. Assim, os movimentos sociais, em suas grandes ações políticas, não cometem crimes contra o Estado, mas apenas expressam a cidadania de pessoas que buscam a consolidação de um autêntico Estado Democrático de Direito.
} 


\title{
REVI STA ELETRÔNI CA DA FACULDADE DE DI REITO DE FRANCA \\ www.revista.direitofranca.br \\ v. 7, n.1, jul/ 2013, ISSN: 1983-4225
}

Estado Democrático de Direito o Judiciário foi elevado a uma posição de destaque para a defesa dos cidadãos. Segundo Luiz Wernneck Vianna:

\begin{abstract}
O aprofundamento do processo da transição, entretanto - em particular após a promulgação da Constituição de 1988, que redefiniu o papel republicano do Poder Judiciário -, e mais a progressiva identificação deste Poder como lugar de ampliação de direitos por parte de uma nova clientela até então distante dele, trouxeram esse 'retardatário' para o primeiro plano da vida pública. ${ }^{7}$
\end{abstract}

Desta forma, o Poder Judiciário deixou de ocupar uma posição secundária entre os outros dois poderes e passou a exercer um papel fundamental para a consolidação do regime democrático. Todavia, esta nova situação não deve levar ao decisionismo ou ao ativismo judicial para atender as novas demandas constitucionais, numa situação onde os juízes não estão sujeitos a nenhum tipo de controle democrático. Todas as decisões judiciais devem ser muito bem fundamentadas, não com base em política, mas com base em toda principiologia da Constituição Federal. Diante disso, é necessário ressaltar que o presente trabalho critica todo tipo de ativismo judicial ou discricionariedade das decisões emitidas pelo Judiciário. Estas posições são próprias de um paradigma positivista do Direito, que já foram superadas pelo constitucionalismo moderno e pela fenomenologia hermenêutica. O novo papel constitucional do Judiciário, que acarretou um aumento considerável de suas atribuições, é próprio do reconhecimento de direitos sociais mais amplos nas Constituições do segundo pósguerra e não deve ser confundido com uma atuação sem limites dos juízes. Desta forma, não é pertinente analisar se existem ativismos bons ou maus, qualquer forma de atuação discricionária do poder judiciário sempre ocorre em detrimento do regime democrático, seja ele mais progressista ou mais conservador.

Portanto, para compreender todas essas questões que envolvem a concretização das políticas públicas de reforma agrária, estabelecidas pela Constituição Federal, primeiramente o trabalho vai analisar a formação histórica do Estado brasileiro, a partir de uma aproximação da tese sustentada por Raymundo Faoro, do Estado patrimonialista e estamental, como obstáculo para uma atuação da administração pública pautada sempre pela constitucionalidade. Logo depois, diante da reconfiguração nas esferas de tensão dos Poderes do Estado, decorrente do novo papel assumido pelo Poder Judiciário no Constitucionalismo

\footnotetext{
${ }^{7}$ Cf. VIANNA, Luiz Werneck; BURGOS, Marcelo Baumann; CARVALHO, Maria Alice Rezende de; MELO, Manuel Palacios Cunha. Corpo e Alma da Magistratura Brasileira, 3a ed., Rio de Janeiro: Editora Revan, 1997, p. 11 e 12.
} 


\section{REVI STA ELETRÔNI CA DA FACULDADE DE DI REITO DE FRANCA \\ www.revista.direitofranca.br \\ v. 7, n.1, jul/ 2013, ISSN: 1983-4225}

Contemporâneo, o trabalho vai analisar a importância da atividade jurisdicional para a concretização das políticas públicas de reforma agrária, compatíveis com as conquistas democráticas do Estado Democrático de Direito.

\section{A FORMAÇÃO DO ESTADO BRASILEIRO: UMA ANÁLISE DO ESTAMENTO BUROCRÁTICO COMO OBSTÁCULO PARA A CONCRETIZAÇÃO DAS POLÍTICAS PÚBLICAS CONSTITUCIONAIS}

Diante de uma nova realidade constitucional, onde demandas sociais e econômicas, acumuladas historicamente, foram constitucionalizadas pelo Estado Democrático de Direito, não é possível que o Estado brasileiro continue operando a partir de um paradigma liberalindividualista, completamente despreparado para lidar com conflitos transindivuais. A Constituição de 1988 é a carta política mais democrática que a sociedade brasileira construiu durante toda a República. Após diversos golpes de Estado, regimes políticos autoritários e a total ausência de liberdade política, a Constituição de 1988, conquistada a duras penas, foi capaz de resgatar as grandes promessas da modernidade, representadas principalmente pela igualdade, justiça social e garantia dos direitos humanos fundamentais. Nesse sentido, para tornar efetiva todas essas conquistas democráticas, faz-se imperioso superar o modelo de Estado patrimonialista e estamental, de origem lusitana, forjado historicamente pela elite brasileira, pois esse estamento burocrático, ao mesmo tempo em que detém o domínio do Estado, instrumentaliza a Constituição a partir de seus interesses privados, o que, conseqüentemente, acaba ocasionando uma forte crise de legalidade ${ }^{8}$ e de constitucionalidade, que impede a construção de um verdadeiro espaço público, capaz de tornar efetivas as conquistas democráticas do Constitucionalismo Contemporâneo.

\footnotetext{
${ }^{8}$ Cf. TOMAZ DE OLIVEIRA, Rafael. Decisão Judicial e o Conceito de Princípio: a hermenêutica e a (in)determinação do Direito, Porto Alegre: Livraria do Advogado Editora, 2008, p. 80 e 81 . É necessário fazer um pequeno esclarecimento para elucidar o que se afirma como legalidade no presente trabalho, pois não é algo que afeta simplesmente a legislação, restringindo-se simplesmente ao que é divulgado constantemente pelo pensamento dogmático jurídico como o “império da lei”, mas em concordância com o pensamento de Rafael Tomaz de Oliveira: “[...] legalidade deve ser entendida como o conjunto de operações do Estado que é determinado não apenas pela lei, mas também pela Constituição - uma vez que seria um contra-senso afirmar uma legalidade que não manifestasse a consagração de uma constitucionalidade - e pela efetividade das decisões judiciais, sob o marco de uma legitimidade democrática. Mais do que isso: legalidade implica na formação de um espaço público de tomada de decisões num âmbito estatal específico e na capacidade de tornar efetivas tais decisões”. Portanto, o mesmo autor afirma que, “[...] a legalidade é uma forma de se constituir o espaço público de maneira que se possa dizer que ele esteja tomado por ela; é um fenômeno complexo, para onde confluem as noções de cidadania e democracia; é o momento em que o espaço público é efetivamente público e não colonizado por interesses privados”.
} 


\section{REVI STA ELETRÔNI CA DA FACULDADE DE DI REITO DE FRANCA \\ www.revista.direitofranca.br \\ v. 7, n.1, jul/ 2013, ISSN: 1983-4225}

De acordo com a posição de Raymundo Faoro, o Estado brasileiro foi formado por um estamento patrimonialista adequado ao modelo tradicional de dominação política, capaz de se amoldar a todos os momentos de transição e perpetuar um controle político onde o exercício do poder não é uma função pública, mas simplesmente objeto de apropriação de interesses privados. Segundo Faoro, esse estamento burocrático jamais correspondeu àquela burocracia moderna, como um aparelhamento neutro, constituído em carreira administrativa e que sempre deve atuar com padrões bem assentados de racionalidade e legalidade. ${ }^{9}$ Assim, colocando-se acima dos demais setores da sociedade brasileira, encontra-se o estamento burocrático, dedicando-se unicamente a tomar conta dos cargos oferecidos pela administração pública e sempre se posicionando no melhor lugar para a defesa de interesses meramente privados, já que, para esse “nobre” setor, o público e o privado nunca estão totalmente separados. Assim, Faoro afirma que:

Sobre a sociedade, acima das classes, o aparelhamento político - uma camada social, comunitária embora nem sempre articulada, amorfa muitas vezes - impera, rege e governa, em nome próprio, num círculo impermeável de comando. Esta camada muda e se renova, mas não representa a nação, senão que, forçada pela lei do tempo, substitui moços por velhos, aptos por inaptos, num processo que cunha e nobilita os recém-vindos, imprimindo-lhes os seus valores. ${ }^{10}$

Desse modo, predomina no Brasil uma concepção político-econômica que aproxima capital e Estado, numa relação completamente perniciosa, fazendo com que o fruto de um empreendimento coletivo, na sua maior parte, seja aplicado na solução dos problemas particulares daqueles que permanecem juntos com os agentes do poder (estamento). Esta situação reforça ainda mais a desigualdade social predominante em terrae brasilis, pois, diante dessas condições, o Estado tem servido muito mais para sustentação de privilégios particulares do que para concretizar as conquistas democráticas do Constitucionalismo Contemporâneo, já que, de acordo com Sérgio Buarque de Holanda, infelizmente “a

\footnotetext{
${ }^{9}$ Cf. WEBER, Max. Economia e Sociedade. Fundamentos da sociologia compreensiva. Vol. II. São Paulo: Editora UNB, 2004. De acordo com Max Weber, diferentemente do estamento burocrático, a burocracia se organiza como uma camada profissional, capaz de assegurar o bom funcionamento do Estado e da administração pública. Desse modo, a burocracia não invade e dirige a esfera econômica, política e financeira, como ocorre com o estamento, mas deve aparecer como um aparelhamento neutro, em qualquer tipo de Estado ou em qualquer forma de organização do poder, permitindo a realização do serviço público de maneira profissional e técnica, distanciando-se das influências político-partidárias. Assim, nos termos de Weber, a burocracia deve ordenar o comportamento humano por meio do exercício da autoridade racional-legal, para o atendimento de objetivos organizacionais gerais, a partir de uma rigorosa divisão de tarefas, com a criação de regras detalhadas e de uma hierarquia que possa garantir sua execução.

${ }^{10}$ Cf. FAORO, Raymundo. Os donos do poder: formação do patronato político brasileiro. $3^{\circ}$ ed., São Paulo: Globo, 2001, p. 824.
} 


\section{REVI STA ELETRÔNI CA DA FACULDADE DE DI REITO DE FRANCA \\ www.revista.direitofranca.br \\ v. 7, n.1, jul/ 2013, ISSN: 1983-4225}

democracia no Brasil foi sempre um lamentável mal-entendido”. ${ }^{11}$ Esse modelo estatal, patrimonialista e estamental, implantado há vários séculos em terrae brasilis, foi capaz de se amoldar a todas as principais transformações sociais e econômicas trazidas pelo capitalismo moderno. De fato, a realidade histórica brasileira demonstrou a persistência secular desse modelo estatal, de onde se armou a formação de um capitalismo politicamente orientado, que transforma o Estado no maior patrocinador da iniciativa privada, fazendo com que o governo esteja em crise quando o assunto é políticas públicas de bem-estar, ${ }^{12}$ mas, por outro lado, cada vez mais eficiente quando é obrigado a alocar recursos para “incentivar” a economia privada. Desse modo, em lugar de um regime político fundado na liberdade individual, onde o empresário deve cuidar e gerir a sua propriedade, de forma a assumir todos os riscos de aplicação do seu capital, aparece uma estrutura político-social que conduz, comanda e supervisiona os negócios privados, fazendo com que apenas uma pequena parcela da sociedade tenha acesso as benesses do Estado, contrariando completamente as conquistas democráticas do Constitucionalismo Contemporâneo. Diante desse estamento burocrático, que há muito tempo vem ocupando a estrutura burocrático-administrativa do Estado, a Constituição acaba sendo instrumentalizada por interesses meramente privados, o que, conseqüentemente, acaba por gerar uma forte crise de legalidade e de constitucionalidade, que impede a construção de um verdadeiro espaço público. É nesse sentido que a maior parte dos financiamentos feitos pelo BNDES, em atividades realizadas por grandes grupos econômicos, pode exemplificar essa situação. Recentemente, apenas na construção de um estádio de futebol, para certo clube do estado de São Paulo, o BNDES será capaz de desembolsar aproximadamente R\$ 400 milhões, em um investimento público de valor extremamente elevado, numa atividade que envolve uma das maiores construtoras desse país, a Odebrecht. Em outro caso, o mesmo banco estava disposto a financiar uma operação de fusão entre duas grandes redes de supermercados, o Pão de Açúcar e o Carrefour, com um aporte de até R\$ 4,5

\footnotetext{
${ }^{11}$ Cf. HOLANDA, Sérgio Buarque de. Raízes do Brasil. $26^{\circ}$ ed., São Paulo: Companhia das Letras, 1995 , p. 160.

${ }^{12}$ Para isso ver a matéria “Reforma agrária, descanse em paz”. In: Carta Capital. 03/08/11, pp. 22/28. De acordo com esta reportagem, os gastos com reforma agrária vêm caindo a cada governo petista, fazendo com que a concentração de terras se mantenha como nos tempos da ditadura militar. A revista demonstra que os gastos efetivos com distribuição de terras declinaram no segundo mandato do presidente Lula, seguindo os mesmos rumos no governo da presidenta Dilma. Não deixa de ser instigante o fato de um partido político da chamada “esquerda” brasileira, como é o caso do PT, aliado histórico das lutas sociais no campo, tenha feito tão pouco pela reforma agrária, já que sua maior liderança política, o ex-presidente Lula, ainda durante a campanha eleitoral de 2002, prometia resolver o problema agrário com uma simples canetada!
} 


\section{REVI STA ELETRÔNI CA DA FACULDADE DE DI REITO DE FRANCA \\ www.revista.direitofranca.br \\ v. 7, n.1, jul/ 2013, ISSN: 1983-4225}

bilhões. ${ }^{13}$ Afinal, quais seriam os critérios para a adoção de prioridades em investimentos com dinheiro público? Diante de tantos problemas sociais, que impedem uma parcela considerável da sociedade brasileira de ter acesso aos benefícios estabelecidos pela Constituição, nada poderia explicar essa realidade, a não ser a origem patrimonialista e estamental do Estado brasileiro, preocupado apenas com o bem-estar-social de uma pequena parcela da sociedade, onde a Constituição é transformada em um território inóspito, espécie de um latifúndio improdutivo, para grande parte dos brasileiros que não têm o mesmo tipo de acesso a esses benefícios. $^{14}$

Por tudo isso, é possível sustentar com Marcelo Neves, que em países de modernidade tardia, como é o caso do Brasil, existem duas categorias de pessoas ${ }^{15}$ : os subintegrados, que dependem do Estado, mas nunca tem acesso as políticas públicas que deveriam ser realizadas por ele, e os sobreintegrados, que dispõe do Estado para a realização de seus projetos privados, mas nunca se subordinam a Constituição. É nesse sentido que o autor afirma:

[...] para os subintegrados, os dispositivos constitucionais têm relevância quase exclusivamente em seus efeitos restritivos de liberdade. Os direitos fundamentais não desempenham nenhum papel significativo no seu horizonte de agir e vivenciar,

\footnotetext{
${ }^{13}$ Cf. FAORO, Raymundo. Democracia Traída. Coletânea de entrevistas de Raymundo Faoro. Rio de Janeiro: Globo, 2008, p. 105 Em entrevista concedida à revista Senhor em outubro de 1988, Faoro foi questionado a respeito da posição ideológica da candidatura de Mario Covas à presidência da República. Perguntado se essa candidatura representava posições políticas consideradas de “esquerda”, sua resposta foi a seguinte: "também há um equívoco cultivado, como se a esquerda fosse estatizante. De verdade, o setor mais lúcido da esquerda quer um Estado mais eficiente. Já os conservadores falam muito contra o Estado, mas, tendo todas as condições de governo, até hoje nunca fizeram nada para que o Estado fosse eficiente. Eles querem o velho Estado patrimonialista, um Estado cujo retrato está na relação dos homens de mais de um bilhão de dólares, os maiores empresários brasileiros. Um empreiteiro, cujo parceiro é o Estado; outro tem televisões, cujo concedente é o Estado; outro é banqueiro, cuja carta patente lhe foi dada pelo Estado e lhe pode ser retirada com um telefonema do gerente do Banco Central; outro, um grande empresário de São Paulo, o maior empresário brasileiro, que é concessionário de minas e outras coisas mais. Contra que Estado eles estão falando? Será que é o Estado que lhes dá concessões, prebendas, cartórios?” É de se perguntar: o Estado brasileiro deixou de ser interventor? Talvez a pergunta deva ser reposicionada: para quem o Estado brasileiro pode intervir?

${ }^{14}$ Cf. STRECK, Lenio Luiz. Jurisdição Constitucional e Hermenêutica: uma nova crítica do Direito. Porto Alegre: Livraria do Advogado, 2002, p. 31.

${ }^{15}$ Cf. LIMA LOPES, José Reinaldo de. O Direito na História. $3^{\circ}$ ed., São Paulo: Editora Atlas, 2009, p. 289. Durante o Império a Constituição de 1824 reconhecia duas categorias de cidadãos: os passivos e os ativos. Os primeiros tinham os direitos civis de liberdade, propriedade e segurança de suas vidas e bens reconhecidos pelo Estado, mas não gozavam do direito de votarem e serem votados; já os cidadãos ativos tinham todos esses direitos reconhecidos pelo Estado e, ao mesmo tempo, gozavam plenamente de todos os direitos políticos. É importante destacar que os escravos não estavam incluídos em nenhuma dessas duas categorias de cidadãos existentes na Constituição do Império. Atualmente, em pleno Estado Democrático de Direito, esse tipo de distinção desapareceu do texto constitucional, já que agora o Brasil possui uma Constituição republicana e democrática. Acontece que o estamento burocrático, que ainda domina o Estado brasileiro, parece não ter se dado conta dessa nova realidade constitucional e, por isso, essa velha discriminação, agora totalmente inconstitucional, insiste em continuar marginalizando uma camada significativa da sociedade brasileira.
} 


\section{REVI STA ELETRÔNI CA DA FACULDADE DE DI REITO DE FRANCA \\ www.revista.direitofranca.br \\ v. 7, n.1, jul/ 2013, ISSN: 1983-4225}

inclusive no concernente à identificação de sentido das respectivas normas constitucionais. ${ }^{16}$

Já com relação aos sobreintegrados, o mesmo autor afirma categoricamente:

[...] em princípio, são titulares de direitos, competências, poderes e prerrogativas, mas não se subordinam regularmente à atividade punitiva do Estado no que se refere aos deveres e responsabilidades. Sua postura em relação à ordem jurídica é eminentemente instrumental: usam, desusam ou abusam-na conforme as constelações concretas e particularistas dos seus interesses. ${ }^{17}$

A generalização destas duas categorias sociais faz implodir a Constituição como ordem básica para a concretização do Estado Democrático de Direito, pois, tanto a subintegração, como a sobreintegração, implicam em uma inclusão insuficiente, com pessoas carentes de cidadania, já que esta pressupõe igualdade de direitos e deveres. Assim, levando em conta esta realidade social, é até "possível” entender a naturalidade com que o pensamento dogmático aceita a criminalização dos delitos menos relevantes, como é o caso do furto e da apropriação indébita, considerados crimes de feição patrimonial não diretamente violentos; ao mesmo tempo, casos de crimes mais graves, como os que envolvem a sonegação fiscal, que têm o condão de prejudicar os interesses difusos e coletivos da sociedade, são deixados a margem do Código Penal, numa situação de clara violação do princípio da isonomia constitucional. Diante desta condição, é muito simples compreender o motivo deste tratamento desigual, pois, no primeiro caso, estão envolvidos principalmente os subintegrados, já com relação à segunda situação, sempre estão presentes os sobreintegrados.

Desta forma, nem mesmo a transição de um regime militar, fortemente autoritário, para governos eleitos democraticamente, tornou possível a consolidação do regime democrático no Brasil. A escassez de instituições políticas estáveis e democráticas, o estabelecimento de um Estado patrimonialista e estamental, acompanhado do estilo personalista de alguns governantes, têm dificultado grandemente o estabelecimento de um autêntico Estado Democrático de Direito. Nesse sentido, Guillermo O’Donnell afirma ser necessária uma segunda transição, muito mais complexa, para a consolidação do regime democrático, pois predomina em países de modernidade tardia uma modalidade peculiar de democracia, profundamente individualista e personalista, denominada pelo autor de democracia delegativa. Segundo ele, “mesmo que a democracia delegativa pertença ao gênero

\footnotetext{
${ }^{16}$ Cf. NEVES, Marcelo. Entre Têmis e Leviatã: uma relação difícil, $2^{\circ}$ ed., São Paulo: Martins Fontes, 2008, p. 248 e 249.

${ }^{17}$ Cf. NEVES, Marcelo. Entre Têmis e Leviatã: uma relação difícil, $2^{\circ}$ ed., São Paulo: Martins Fontes, 2008, p. 250.
} 


\section{REVI STA ELETRÔNI CA DA FACULDADE DE DI REITO DE FRANCA \\ www.revista.direitofranca.br \\ v. 7, n.1, jul/ 2013, ISSN: 1983-4225}

democrático, seria difícil encontrar algo que seja mais estranho, quando não hostil, à construção e ao fortalecimento de instituições políticas democráticas”. ${ }^{18}$ Assim, para atender as demandas sociais e econômicas acumuladas ao longo da história, é necessário que o Estado tenha uma maior eficiência em suas ações políticas e jurídicas, o que faz necessário um Estado constitucionalmente forte e eficiente, não no sentido do nível de coerção imposto sobre os indivíduos, mas com instituições consolidadas democraticamente, capazes de concretizar as políticas públicas do Estado Democrático de Direito.

Durante a década de 1990, principalmente a partir do governo do presidente Fernando Henrique Cardoso (1994 - 2002), o Estado passou a sofrer grande oposição do pensamento neoliberal. De acordo com essa corrente, a modernidade havia sido superada e, por essa razão, o Estado deveria diminuir seu espaço de intervenção nas atividades econômicas, tornando-se uma instituição anacrônica diante das novas relações estabelecidas pela globalização. Com efeito, essa forte tendência favorável a privatização do Estado agravou ainda mais a crise de legalidade e de constitucionalidade que afeta o Estado brasileiro, já que essa posição reforçou a ausência de um verdadeiro espaço público, tornando cada vez mais distante a concretização dos direitos sociais previstos na Constituição. Assim, é possível destacar, que o efeito das reformas neoliberais foi totalmente catastrófico em países que não passaram nem mesmo pelo Estado Social, ${ }^{19}$ como é o caso do Brasil, implicando no agravamento dos problemas sociais, políticos e econômicos.

Em oposição ao pensamento neoliberal, é importante destacar que o surgimento do Estado Moderno foi um acontecimento histórico muito relevante, pois apareceu em oposição a uma estrutura de poder totalmente fragmentada, conveniente as relações sociais, econômicas e políticas estabelecidas no medievo. Inicialmente, o Estado moderno apareceu como absolutista, centralizando e racionalizando toda a estrutura de poder nas mãos do Estado, estabelecendo um exército nacional permanente, um corpo diplomático profissionalizado e

\footnotetext{
${ }^{18}$ Cf. O’DONNELL, Guillermo. Democracia delegativa? In: Novos Estudos Cebrap, n. 31, out/1991, p. 33.

${ }^{19}$ Cf. STRECK, Lenio Luiz. Hermenêutica Jurídica E $(m)$ Crise. $10^{\circ}$ ed., Porto Alegre: Livraria do Advogado, 2011, p. 27 e 28. Segundo o professor Lenio, os benefícios de um Estado intervencionista-desenvolvimentistaregulador foram sentidos apenas pela elite brasileira. Ele afirma que, "o Estado interventor-desenvolvimentistaregulador, que deveria fazer esta função social, foi - especialmente no Brasil - pródigo (somente) para com as elites, enfim, para as camadas médio-superiores da sociedade, que se apropriaram / aproveitaram de tudo desse Estado, privatizando-o, dividindo / loteando com o capital internacional os monopólios e os oligopólios da economia e, entre outras coisas, construindo empreendimentos imobiliários com o dinheiro do fundo de garantia (FGTS) dos trabalhadores, fundo esse que, em 1966, custou a estabilidade no emprego para os milhões de brasileiros!”
} 


\section{REVI STA ELETRÔNI CA DA FACULDADE DE DI REITO DE FRANCA \\ www.revista.direitofranca.br \\ v. 7, n.1, jul/ 2013, ISSN: 1983-4225}

uma estrutura burocrática capaz de cuidar das atividades do Estado; ${ }^{20}$ mais tarde, após as revoluções do século XVIII, o Estado surgiu em sua modalidade liberal, com o reconhecimento dos direitos civis e o estabelecimento de limitações constitucionais para o exercício do poder político; ${ }^{21}$ por último, o Estado Contemporâneo, em suas diversas modalidades, ampliou a sua atuação constitucional, no sentido de garantir a máxima aplicabilidade dos direitos humanos fundamentais, pois, segundo Konrad Hesse, o Estado Democrático de Direito foi constituído em colaboração social, superando a velha idéia de contraposição entre Estado e sociedade civil. Assim, a “[...] vida social não é mais possível sem a configuração organizadora, planificadora, responsável pelo Estado. Ao contrário, o Estado democrático constitui-se somente na colaboração social”. ${ }^{22}$

Desse modo, para compreender o novo modelo de Estado (e de Direito) estabelecido pela Constituição Federal, é necessária a construção de possibilidades para sua interpretação. Nesse sentido, constitui um grande equívoco a compreensão do Estado Democrático de Direito a partir dos pré-juízos proporcionados pelo paradigma liberal-individualistanormativista, pois essa postura acaba esvaziando as possibilidades de construção desse novo modelo estatal.

Portanto, ao estabelecer o Estado Democrático de Direito, a Constituição brasileira consagrou o princípio da democracia econômica, social e cultural, impondo uma obrigação constitucional aos órgãos de direção político-administrativa, de pautarem suas respectivas atividades de acordo com este princípio. Desse modo, para construir um autêntico Estado Democrático de Direito, faz-se necessário superar o paradigma privatista de Estado, ainda existente em terrae brasilis, e que se encontra completamente distante do horizonte de sentido proporcionado pelas conquistas democráticas. O Constitucionalismo Contemporâneo, a partir de todas as transformações ocorridas no Direito, encontra-se em completa desconformidade com essa modalidade estatal, onde ainda predomina um modelo patrimonialista e estamental, capaz de continuar adiando ad eternum a concretização das conquistas democráticas.

\footnotetext{
${ }^{20}$ Cf. MATEUCCI, Nicola. Organización del poder y liberdad. Historia del constitucionalismo moderno. Madrid: Trotta, 1998, p. 29 a 41.

${ }^{21}$ Cf. ENTERRÍA, Eduardo García de. La lengua de los derechos. La formacion del Derecho Público europeo trás la Revolución Francesa, Madrid: Alianza Editorial, 1995, p. 136 a 145.

${ }^{22}$ Cf. HESSE, Konrad. Elementos de Direito Constitucional da República da Alemanha, 20ª ed., Porto Alegre: Editora Sergio Antonio Fabris, 1998, p. 34.
} 


\section{REVI STA ELETRÔNI CA DA FACULDADE DE DIREITO DE FRANCA \\ www.revista.direitofranca.br \\ v. 7, n.1, jul/ 2013, ISSN: 1983-4225}

\section{O PAPEL DO PODER JUDICIÁRIO NA CONCRETIZAÇÃO DAS POLÍTICAS PÚBLICAS DE REFORMA AGRÁRIA}

Ao longo da história constitucional as mudanças de paradigmas estatais foram reconfigurando às relações institucionais entre os três Poderes. Dessa forma, durante a formação do Estado Liberal de Direito havia um contexto de forte preocupação com a limitação do poder estatal, fazendo com que a predominância na atuação institucional ficasse com o Poder Legislativo, organizado nesse período como representante legítimo do povo, para coibir o excesso de poder exercido pelas monarquias européias; mais tarde, com a formação do Estado Social de Direito, a predominância na atuação institucional foi transferida para o Poder Executivo, como condição necessária para a realização das políticas públicas contidas nesse modelo estatal, marcado por características fortemente intervencionistas na economia; por último, com o advento da nova Constituição e de seu caráter compromissório, questões historicamente relegadas ao campo da política foram incorporadas pelo Direito, fazendo com que as crescentes demandas sociais passassem a buscar a sua realização no Poder Judiciário. Assim, a partir da nova carta constitucional, promulgada em 1988, houve uma redefinição do papel a ser exercido pelo Poder Judiciário, no sentido de buscar a concretização do Estado Democrático de Direito, pois introduziu na Constituição um sentido promocional prospectivo, obrigando o Estado a realizar os direitos humanos fundamentais. Desse modo, após diversos golpes de Estado, regimes políticos autoritários e a total ausência de liberdade política, a Constituição de 1988 foi capaz de resgatar as grandes promessas da modernidade, representadas principalmente pela igualdade, justiça social e garantia dos direitos humanos fundamentais. Diante dessa nova realidade constitucional, onde demandas sociais e econômicas, acumuladas historicamente, foram constitucionalizadas pelo Estado Democrático de Direito, a atividade jurisdicional ganhou um papel de maior relevância para a concretização das conquistas sociais do Estado Democrático de Direito. Nesse sentido, os casos que envolvem as políticas públicas de reforma agrária ilustram muito bem esta situação, pois com a constitucionalização de um projeto que democratiza o acesso a propriedade da terra, o problema da concentração fundiária ${ }^{23}$ deixou de ser debatido estritamente no campo

\footnotetext{
${ }^{23}$ Cf. PRADO Jr., Caio. Evolução Política do Brasil. $21^{\circ}$ ed., São Paulo: Editora Brasiliense, 2007, p. 17 a 23. A estrutura agrária brasileira sempre teve como base a grande exploração rural, a monocultura e o trabalho degradante. Logo no início da colonização, a pequena propriedade não encontrou uma situação muito favorável
} 


\section{REVI STA ELETRÔNI CA DA FACULDADE DE DI REITO DE FRANCA \\ www.revista.direitofranca.br \\ v. 7, n.1, jul/ 2013, ISSN: 1983-4225}

da política e também passou a ter relevância jurídica. No entanto, esse novo papel constitucional do Poder Judiciário não deve ser confundido com uma atuação sem limites dos juízes, com uma postura discricionária que pode colocar em risco toda a construção democrática. A atividade jurisdicional não deve ser encarada como a solução para as deficiências institucionais do Estado brasileiro, pois, segundo o professor Lenio, “o Judiciário não pode ser a solução mágica para os problemas dos fracassos e insuficiências de políticas de welfare state". 24

Assim, faz-se necessário desvelar novos caminhos para os juristas, superando aquilo que o sentido comum teórico ocultou, ao provocar o esquecimento do ser do Direito, e que, conseqüentemente, vem evitando o acontecer do novo Constitucionalismo, pois, grande parte da comunidade jurídica ainda se encontra inserida no pensamento metafísico, onde o mundo prático é completamente esquecido pela teoria ${ }^{25}$ apresentada pelo pensamento dogmático. Nesse sentido, o ensino do Direito, na forma como foi estabelecido historicamente no Brasil, vem contribuindo para agravar esta situação, ao reproduzir um discurso jurídico imerso no

\footnotetext{
para seu desenvolvimento, já que o desbravamento de um território extenso exigia grandes investimentos por parte dos proprietários, numa condição claramente inacessível para o estabelecimento do trabalho livre. Somente na instalação dos engenhos de açúcar, principal atividade econômica durante o período colonial, os proprietários eram obrigados a investir valores muito elevados, o que, conseqüentemente, acabava dificultando a atuação dos pequenos proprietários. Desse modo, tornava-se praticamente impossível aos pequenos lavradores, desprovidos de qualquer tipo de recurso, se adaptarem a este sistema. Além de todos estes problemas, outro obstáculo que também dificultava a situação dos pequenos produtores era a completa ausência de um mercado interno para o escoamento de seus produtos, pois, diante das condições da população colonial, constituída na sua maior parte por escravos e semi-escravos negros, índios e mestiços, os pequenos lavradores não tinham grandes opções para negociar a sua produção, já que as cidades praticamente inexistiam e as grandes propriedades rurais produziam praticamente todo o necessário para o seu consumo interno. Desse modo, frente a estas condições, era praticamente impossível o desenvolvimento da pequena propriedade em terrae brasilis, pois toda a economia agrária colonial estava fundada unicamente no grande domínio rural. Nesse sentido, a escolha feita por Portugal, de um modelo de ocupação territorial baseado em grandes unidades produtivas, determinou a estrutura agrária brasileira. Hodiernamente, o latifúndio ainda se apresenta como base do modelo de desenvolvimento estabelecido no campo, recebendo a maior parte dos recursos disponibilizados pelo Estado.

${ }^{24}$ Cf. STRECK, Lenio Luiz. Hermenêutica Jurídica E(m) Crise. $10^{\circ}$ ed., Porto Alegre: Livraria do Advogado, 2011, p. 64.

${ }^{25}$ Cf. STRECK, Lenio Luiz. O que é isto - decido conforme minha consciência? - Porto Alegre: Livraria do Advogado Editora, 2010, p. 59. De acordo com o professor Lenio, a separação entre teoria e prática apareceu na filosofia grega, com a metafísica clássica e, mais tarde, foi retomada pela metafísica moderna. Segundo o professor, “[...] a razão prática nos vem desde a filosofia grega, quando Aristóteles delimitou uma filosofia teórica (que pergunta pela verdade ou pela falsidade) e uma filosofia prática (que pergunta pelo certo e pelo errado). Na primeira, está em jogo uma observação de uma determinada realidade, ao passo que, na segunda, tem-se o questionamento de uma ação concreta”. Com relação à modernidade, “a problematização entre razão teórica e razão prática foi retomada por Kant em sua Crítica da Razão Pura e na Crítica da Razão Prática. O que há em comum entre Kant e Aristóteles é que em ambos há uma barreira que separa a filosofia teórica da prática e nenhum deles conseguiu explicar como a filosofia teórica pode determinar a filosofia prática ou viceversa”. Este dualismo estabelecido pelo pensamento metafísico ainda permanece presente no pensamento dogmático.
} 


\section{REVI STA ELETRÔNI CA DA FACULDADE DE DI REITO DE FRANCA \\ www.revista.direitofranca.br \\ v. 7, n.1, jul/ 2013, ISSN: 1983-4225}

senso comum teórico de manuais, totalmente desprovidos de qualquer conteúdo científico; a hermenêutica, ainda praticada nestes cursos, continua insistindo em estudar os métodos tradicionais de interpretação, seguindo uma linha de pensamento que considera o Direito apenas como uma mera racionalidade instrumental. ${ }^{26}$ Por conseguinte, o Direito aparece como uma ciência lógico-formal, preocupada estritamente com a elaboração de uma epistemologia jurídica que se encontra completamente distante dos problemas sociais, políticos, econômicos e ideológicos, o que contribui para que o jurista permaneça completamente alienado da sua realidade histórica, colaborando para a inefetividade das políticas públicas de reforma agrária. Dessa forma, o paradigma positivista, em suas diversas modalidades, vai resistindo firmemente a viragem ontológico-linguistica, pois, no Direito, muitas das teorias que se autodenominam pós-positivistas, acabam por repristinar o que há de fundamental na Teoria Pura do Direito ${ }^{27}$, que é a decisão como ato de vontade, reforçando ainda mais a discricionariedade como resposta para o problema do déficit de concretização constitucional em terrae brasilis, situação em que, com toda certeza, acaba acarretando todo tipo de arbitrariedade praticado pelo Poder Judiciário.

\subsection{A SUPERAÇÃO DO POSITIVISMO JURÍDICO COMO CONDIÇÃO PARA UMA ATIVIDADE JURISDICIONAL SEM DISCRICIONARIEDADE}

O positivismo exegético foi a primeira manifestação do pensamento positivista no Direito. Após a revolução francesa e o movimento codificador, a lei apareceu como instrumento jurídico capaz de resolver e abarcar todos os fatos sociais, reduzindo o ato interpretativo a uma análise meramente sintática, onde a conexão lógica dos signos que compõem o texto legal era suficiente para a sua compreensão. Esse movimento apareceu na França, por meio da Escola da Exegese, e na Alemanha, por meio da Jurisprudência dos

\footnotetext{
${ }^{26}$ Cf. FERRAZ Jr., Tércio Sampaio. Introdução ao estudo do direito. São Paulo: Atlas, 1987, p. 49. Em concordância com o professor Tercio, "é preciso reconhecer que, nos dias atuais, quando se fala em Ciência do Direito, no sentido do estudo que se processa nas Faculdades de Direito, há uma tendência em identificá-la com um tipo de produção técnica, destinada apenas a atender às necessidades do profissional (o juiz, o promotor, o advogado) no desempenho imediato de suas funções. Na verdade, nos últimos cem anos, o jurista teórico, pela sua formação universitária, foi sendo conduzido a esse tipo de especialização, fechada e formalista”.

${ }^{27}$ Cf. KELSEN, Hans. Teoria Pura do Direito, $7^{\circ}$ ed., Trad. João Baptista Machado. São Paulo: Martins Fontes, 2006, p. 392.
} 


\section{REVI STA ELETRÔNI CA DA FACULDADE DE DI REITO DE FRANCA \\ www.revista.direitofranca.br \\ v. 7, n.1, jul/ 2013, ISSN: 1983-4225}

Conceitos $^{28}$. Dessa forma, o professor Luis Alberto Warat afirmava, “que a primeira etapa (do positivismo jurídico) compreende a época da conceitualização dos textos legais. Esta se baseia no pressuposto de que não há mais direito que o ordenamento jurídico estabelecido através das leis validamente ditadas e vigentes”. ${ }^{29}$ Para superar certas limitações existentes nesse positivismo primitivo surgiu o positivismo normativista, preocupado principalmente com o problema da indeterminação do sentido do Direito e com o esgotamento do método sintáticosemântico de interpretação dos códigos. É nesse contexto que aparece a Teoria Pura do Direito, de Hans Kelsen, com o intuito de construir uma teoria do Direito com maior rigor científico e reforçar o método analítico apresentado pelos conceitualistas, em contraposição a Jurisprudência dos Interesses e a Escola do Direito Livre. Para Kelsen, estas duas correntes do pensamento jurídico favoreciam a perda do rigor jurídico no momento da interpretação do Direito, pois permitiam o surgimento de argumentos psicológicos, políticos e ideológicos. Desse modo, Kelsen buscou construir uma Ciência do Direito que não sofresse nenhum tipo de influência político-ideológica, numa relação muito próxima com o pensamento neopositivista desenvolvido pelo Círculo de Viena. ${ }^{30}$ Ao mesmo tempo, Kelsen acabou reproduzindo a separação entre racionalidade teórica e racionalidade prática, elemento que perpassou por toda a tradição do pensamento metafísico. Assim, Kelsen afastou os problemas mais pragmáticos do Direito para se dedicar principalmente a construção de uma epistemologia do Direito, capaz de anular qualquer elemento em condição de prejudicar a pureza e o rigor científico de sua teoria. Nesse sentido, o professor Warat afirmava que,

A Teoria Pura do Direito, ao ser reduzida a um conceitualismo presente tanto no idealismo crítico como no positivismo lógico, consegue eliminar de sua problemática a discussão sobre os fatores codeterminantes da realidade jurídica, como também sobre o papel social e político do Direito e as dimensões ideológicas dos diversos discursos jurídicos enquanto prática jurídica concreta. ${ }^{31}$

\footnotetext{
${ }^{28}$ Cf. STRECK, Lenio Luiz. Hermenêutica Jurídica E(m) Crise. $10^{\circ}$ ed., Porto Alegre: Livraria do Advogado, 2011, p. 119 e 120.

${ }^{29}$ Cf. WARAT, Luis Alberto. Introdução Geral ao Direito II. Porto Alegre: Editor Sergio Antonio Fabris, 1995 , p. 17.

${ }^{30}$ Cf. REALE, Giovane; ANTISERI, Dario. História da Filosofia. III: Do Romantismo até nossos dias. São Paulo: Paulus, 1991, p. 990. De acordo com Giovane Reale e Dario Antiseri, “o pensamento desse grupo adquiriu a denominação de neopositivismo ou positivismo lógico e se caracterizou pela firme atitude antimetafísica e por toda uma série de aprofundadas análises de grande relevância sobre a linguagem, a estrutura e os métodos das ciências naturais e sobre os fundamentos da matemática”. Assim, a partir da influência do Círculo de Viena, é possível compreender a preocupação de Kelsen com a construção de uma epistemologia Direito, livre das influências político-ideológicas.

${ }^{31}$ Cf. WARAT, Luis Alberto. Introdução Geral ao Direito II. Porto Alegre: Editor Sergio Antonio Fabris, 1995 , p. 132.
} 


\section{REVI STA ELETRÔNI CA DA FACULDADE DE DI REITO DE FRANCA \\ www.revista.direitofranca.br \\ v. 7, n.1, jul/ 2013, ISSN: 1983-4225}

Dessa forma, para o positivismo kelseniano, a interpretação feita pelo órgão aplicador do Direito é completamente diferente da interpretação realizada pela ciência do Direito, pois, no primeiro caso, a interpretação ocorre como ato de vontade, permitindo ao órgão aplicador do Direito uma escolha entre diversas possibilidades existentes; já no segundo caso, a interpretação efetuada pela epistemologia do Direito é um ato de conhecimento, preocupado apenas com o estabelecimento das possíveis significações de uma norma jurídica e, portanto, devendo afastar qualquer tentativa de univocidade do significado da norma, já que Kelsen considerava como ficção política a tentativa de formar uma resposta correta. Desse modo, para o positivismo normativista, a ciência do Direito não deve se preocupar com o problema da decisão judicial, pois, diante da separação entre racionalidade teórica e racionalidade prática, estabelecida pelo pensamento metafísico, toda atividade jurisdicional foi reduzida a simples escolha de várias respostas, ou seja, a decisão como um ato discricionário.

Alguns setores do pensamento jurídico crítico compreenderam de maneira equivocada todas essas posições estabelecidas por Kelsen e, diante da tentativa de superação do positivismo normativista, acabaram apostando em teses voluntaristas, que apenas reproduziram as mesmas posições existentes no oitavo capítulo da Teoria Pura do Direito. Desse modo, o movimento do Direito livre, na França, o realismo jurídico, norte-americano, e a Jurisprudência dos Interesses, na Alemanha, não conseguiram escapar da armadilha da discricionariedade judicial, ao tentar libertar os juízes das rígidas estruturas formais. É possível afirmar a mesma coisa com relação ao movimento do Direito alternativo, pois tentou transformar o Direito em um mero instrumento político-ideológico dos movimentos sociais, adequado apenas a atuação política de alguns juristas considerados mais "progressistas”. ${ }^{32}$ Em tempos de Constitucionalismo Democrático é extremamente arriscado apostar em teses

\footnotetext{
${ }^{32}$ Cf. NEVES, Marcelo. Entre Têmis e Leviatã: uma relação difícil, $2^{\circ}$ ed., São Paulo: Martins Fontes, 2008, p. 255 e 256. Em que pese à importância do Direito alternativo na luta contra o regime militar e toda a sua estrutura legal autoritária, atualmente o Brasil possui uma Constituição democrática e, portanto, muito mais que uma alternatividade a legalidade, é necessário lutar pelo estabelecimento e concretização da estrutura legal e constitucional. Nesse sentido, de acordo com Marcelo Neves, "no Brasil, não se trata primariamente do problema de esferas jurídicas alternativas em relação a legalidade estatal, mas sim da ausência ou fragilidade destas. [...] O que se observa é uma miscelânea social de códigos e critérios de comportamento, com efeitos autodestrutivos e heterodestrutivos em todas as esferas de ação, especialmente no que concerne ao direito. A situação é bem mais grave do que se pode inferir de conceitos como "direito alternativo", "uso alternativo do direito" (que implica uma visão instrumental do direito) e "pluralismo jurídico", os quais, no contexto da relação entre direito, Estado e sociedade no Brasil, transformam-se freqüentemente em meros slogans. Nessas circunstâncias, a cultura dominante é a da ilegalidade. Por conseguinte, em vez de alternativa à legalidade, cabe antes falar da legalidade como uma alternativa”.
} 


\section{REVI STA ELETRÔNI CA DA FACULDADE DE DI REITO DE FRANCA \\ www.revista.direitofranca.br \\ v. 7, n.1, jul/ 2013, ISSN: 1983-4225}

voluntaristas para a aplicação do Direito e, portanto, faz-se necessária a superação de todas essas posições que, de alguma maneira, confiaram na vontade dos magistrados como condição para concretizar as conquistas constitucionais do Estado Democrático de Direito.

Assim, é no pensamento pós-positivista, com Ronald Dworkin, que a questão da discricionariedade será tratada com maior afinco, levando em consideração a interpenetração entre direito e política e o vínculo existente entre direito e moral, numa reflexão completamente oposta as posições assumidas pelo positivismo. Dessa maneira, a contribuição de Dworkin é de fundamental importância, pois, ao defender por meio da integridade do Direito a possibilidade da existência de uma resposta correta para os problemas jurídicos, Dworkin superou a discricionariedade judicial $^{33}$ e passou a fornecer mecanismos mais adequados para a concretização dos princípios que orientam a formação do Estado Democrático de Direito. Dessa forma, Dworkin enfrentou um problema que não havia recebido a devida atenção pelo pensamento positivista, como a interpretação e os limites da decisão judicial, já que, nesta corrente de pensamento, diante de uma posição conceitualista da regra, os juristas aceitam antecipadamente múltiplas respostas, sem nenhum vínculo direto com o mundo prático, ${ }^{34}$ considerando possível o esgotamento dos significados dos textos in abstracto. Com Dworkin, a hermenêutica não nega a existência de múltiplos significados para um texto, mas rejeita as posturas analíticas que tentam estabelecer o sentido antes mesmo da aplicação da norma. Desse modo, para buscar a resposta correta é necessário um esforço de reconstrução institucional do Direito, a partir da coerência e da integridade, pois:

As proposições dependem do contexto em que são situadas, do seu contexto
histórico, cultural e até do contexto subjetivo. O que significa isso? Que é preciso
interpretar a linguagem, interpretar as proposições e talvez descobrir que há uma
verdade que é o lugar da proposição. ${ }^{35}$

Para falar em respostas corretas no Direito não é preciso congelar o sentido das normas, numa tentativa de interpretar a partir de uma posição estabelecida fora da história, como se fosse possível esse deslocamento para fora de uma determinada cultura e de um

\footnotetext{
${ }^{33}$ Cf. TOMAZ DE OLIVEIRA, Rafael Tomaz de. Decisão Judicial e o Conceito de Princípio: a hermenêutica e a (in)determinação do Direito, $1^{\circ}$ ed., Porto Alegre: Livraria do Advogado Editora, 2008, p. 216. Segundo Rafael Tomaz de Oliveira, "[...] fica claro porque Dworkin não aceita nenhum tipo de discricionariedade judicial: permitir que o juiz decida de modo a inovar na seara jurídica pode representar um exercício arbitrário (não justificado em princípios da comunidade moral) da coerção estatal colocando-se no tênue liame que sustenta o exercício legítimo da força e a exceção”.

${ }^{34}$ Cf. TOMAZ DE OLIVEIRA, Rafael Tomaz de. Decisão Judicial e o Conceito de Princípio: a hermenêutica e a (in)determinação do Direito, $1^{\circ}$ ed., Porto Alegre: Livraria do Advogado Editora, 2008, p. 179 e 180.

${ }^{35}$ Cf. STEIN, Ernildo. Aproximações sobre Hermenêutica, $2^{\circ}$ ed., Porto Alegre: EDIPUCRS, 2010, p. 20.
} 


\section{REVI STA ELETRÔNI CA DA FACULDADE DE DI REITO DE FRANCA \\ www.revista.direitofranca.br \\ v. 7, n.1, jul/ 2013, ISSN: 1983-4225}

determinado contexto. No paradigma positivista, o mundo prático estava obnubilado pelas conceitualizações metafísicas e, por isso, a tentativa de abarcar todas as futuras hipóteses de aplicação e interpretação, como acontece com as súmulas vinculantes, no formato adotado pelos tribunais em terrae brasilis, acabava transformando a linguagem em um simples veículo de conceitos abstratos, com a pretensão de alcançar a totalidade dos casos concretos. É preciso compreender que não existem mais modelos fixos, onde os juristas estariam previamente constrangidos a fazer suas interpretações. Dessa forma, a partir da hermenêutica ocorre uma libertação de conteúdos rígidos, pois a linguagem, enquanto condição de possibilidade para a compreensão do Direito, sempre será condicionada por processos históricos e culturais.

Quando Dworkin demonstra a possibilidade de respostas corretas no Direito, não o faz no sentido de reproduzir o velho conceitualismo presente no pensamento positivista, mas sim no sentido de enfrentar a indeterminação do Direito, rejeitando toda a idéia de delegação ao juiz para preenchimento das chamadas lacunas. Desse modo, para enfrentar a discricionariedade, toda interpretação jurídica deverá ser perpassada por argumentos de princípio, numa construção coerente que leve em conta uma teoria da constituição, uma teoria da legislação e uma teoria dos precedentes, sempre pensados segundo os postulados da equidade e da integridade, que servirão para fundamentar e justificar a decisão judicial. Assim, Dworkin não está resgatando uma espécie de completude metafísica do Direito, mas, pelo contrário,

Dworkin reconhece uma insuficiência do modelo estritamente teórico de fundamentação, mas debela qualquer possibilidade de lacuna visto que, para ele, a argumentação jurídica está vinculada a critérios práticos de justificação que remetem para padrões prévios de conduta chamados princípios. ${ }^{36}$

Portanto, o “método” do juiz Hercules, preconizado por Dworkin, pressupõe que em toda decisão os juízes estão obrigados a justificar e fundamentar suas posições, num contexto que deve envolver um argumento de princípio, sempre buscando uma reconstrução narrativa do Direito colocado em questão. Dessa forma, Dworkin apresentou uma teoria pragmática, onde o Direito aparece como uma prática interpretativa sempre preocupada com o resultado da decisão, o que faz com que o Poder Judiciário tenha que abandonar as velhas posições

\footnotetext{
${ }^{36}$ Cf. TOMAZ DE OLIVEIRA, Rafael Tomaz de. Decisão Judicial e o Conceito de Princípio: a hermenêutica e a (in)determinação do Direito, $1^{\circ}$ ed., Porto Alegre: Livraria do Advogado Editora, 2008, p. 177.
} 


\section{REVI STA ELETRÔNI CA DA FACULDADE DE DI REITO DE FRANCA \\ www.revista.direitofranca.br \\ v. 7, n.1, jul/ 2013, ISSN: 1983-4225}

discricionárias a favor de uma postura que respeite a coerência de todos os princípios que compõem a integridade moral de uma comunidade.

\subsection{A DEMANDA CHEGA A JUÍZO: O PODER JUDICIÁRIO DIANTE DA INEFETIVIDADE DAS POLÍTICAS PÚBLICAS DE REFORMA AGRÁRIA}

Diante do descaso da administração pública federal com o problema agrário, o Poder Judiciário é acionado para que se manifeste a respeito das constantes ações políticas realizadas pelos movimentos sociais, que atuam no sentido de pressionar o Estado para que as conquistas constitucionais sejam devidamente efetivadas. ${ }^{37}$ Dessa forma, é necessário reavaliar todo o quadro de valores tradicionais que vêm orientando a atuação jurisdicional, por meio de uma interpretação literal da lei civil, que simplesmente considera a propriedade privada da terra como um direito absoluto. Nesse sentido, não é mais possível a permanência de uma formação privatista entre os juristas, colocando-se em completa oposição com os princípios que orientam o Estado Democrático de Direito e fazendo com que o Poder Judiciário considere como esbulho possessório todas as ocupações pacíficas realizadas em terras de extensões latifundiárias, que não cumprem a função social estabelecida pela Constituição Federal. Nessa perspectiva, o deferimento da reintegração de posse, pelo Poder Judiciário, ao titular do domínio que não cumpre as exigências constitucionais, para a proteção da sua propriedade, está resguardando uma verdadeira violação a Constituição e contribuindo para o adiamento da concretização das políticas públicas de reforma agrária. Deste modo, conforme a afirmação de Luiz Edson Fachin:

[...] é defensável concluir que é incongruente com a norma constitucional e a mens legis deferir proteção possessória ao titular de domínio cuja propriedade não cumpre integralmente sua função social, inclusive (e especialmente) no tocante ao requisito da exploração racional. A liminar que seja deferida concedendo a reintegração de

\footnotetext{
37 Cf. FERNANDES, Florestan. Sociedade de Classe e Subdesenvolvimento, $3^{\circ}$ ed., Rio de Janeiro: Zahar Editores, 1975, p. 194. Dessa forma, a luta pela reforma agrária é retomada, como uma forma de resistência contra uma política de desenvolvimento agropecuário excludente, onde, historicamente, a grande massa de trabalhadores rurais sempre esteve em situação de extremo pauperismo. Assim, o sociólogo Florestan Fernandes afirma que, "vastas proporções da população brasileira, vinculadas à economia agrária, vêem-se permanentemente dissociadas da ordem social competitiva ou dela participam de forma esporádica, segmentária e superficial. Tudo se passa como se o desenvolvimento capitalista apenas tivesse vigência em algumas partes da sociedade nacional, precisando excluir e sacrificar as demais, para ter viabilidade e expandir-se. Não há a menor dúvida de que essa situação acarreta a existência de tensões latentes e abertas nos setores mais sacrificados do mundo agrário; [...]”.
} 


\section{REVI STA ELETRÔNI CA DA FACULDADE DE DI REITO DE FRANCA \\ www.revista.direitofranca.br \\ v. 7, n.1, jul/ 2013, ISSN: 1983-4225}

posse de imóvel nessa condição pode até atender a dogmática do Código Civil, mas se choca de frente com o novo texto constitucional. ${ }^{38}$

Em presença de um novo contexto histórico, onde o Estado Democrático de Direito amplia os direitos de setores antes marginalizados pela sociedade brasileira, é imprescindível vislumbrar uma atuação pautada pela constitucionalidade, quando o Poder Judiciário analisa casos que envolvem a questão agrária, superando uma postura tradicional que reduz a função jurisdicional a um simples exercício mecânico de silogismo jurídico. Para uma verdadeira compreensão desses novos desafios, postos ao Poder Judiciário, é necessário que os juristas levem em conta a formulação de novas construções teóricas, capazes de garantir uma maior efetividade dos direitos fundamentais. O positivismo jurídico não é capaz de atender a complexidade dos novos problemas hodiernos, como acontece com a questão agrária, embora ainda existam alguns casos de juristas que insistem em analisar os problemas do Direito a partir desta corrente de pensamento.

Desta forma, o Judiciário deverá interpretar os dispositivos infraconstituiconais, que tratam da reforma agrária, a partir dos princípios que orientam a Constituição, em vez de continuar fazendo o caminho inverso, ao analisar a Constituição a partir do Código Civil. É em coerência com os arts. $1^{\circ}$ e $3^{\circ}$ da Constituição Federal, que enumeram respectivamente os princípios e os objetivos fundamentais da República Federativa do Brasil, que a interpretação a respeito da reforma agrária deve se apoiar. Nesse sentido, segundo Gilberto Bercovici, “as soluções dadas pelo intérprete e pelo aplicador da Constituição devem estar adequadas e ser coerentes com a ideologia constitucionalmente adotada, que os vincula. A Constituição de 1988 é voltada à transformação da realidade”. ${ }^{39}$

Assim, com a demora do Estado brasileiro para implementar a reforma agrária constitucional, é possível constatar o grande aumento da violência contra os trabalhadores rurais sem-terra. De acordo com os dados da CPT (Comissão Pastoral da Terra), no primeiro semestre de 2010 ocorreram 366 conflitos no campo, envolvendo 193.174 pessoas, com 12 assassinatos, 44 tentativas de assassinato, 22 ameaças de morte, seis pessoas torturadas e 90 presas. Além disso, 393 pessoas foram expulsas da terra por ações ilegais de latifundiários, sempre acompanhados por seus jagunços fortemente armados e 4.475 pessoas foram

\footnotetext{
${ }^{38}$ Cf. FACHIN, Luiz Edson. A justiça dos conflitos no Brasil. In: A questão Agrária e a Justiça. Juvelino José Strozake (org.). São Paulo: Editora Revista dos Tribunais, 2000, p. 285.

${ }^{39}$ Cf. BERCOVICI, Gilberto. A problemática da constituição dirigente: algumas considerações sobre o caso brasileiro. In: Revista de Informação Legislativa n. 142. Brasília, 1999, p. 46.
} 


\section{REVI STA ELETRÔNI CA DA FACULDADE DE DI REITO DE FRANCA \\ www.revista.direitofranca.br \\ v. 7, n.1, jul/ 2013, ISSN: 1983-4225}

despejadas por ordem do Poder Judiciário. ${ }^{40}$ Uma situação alarmante, onde o Poder Judiciário também tem a sua parcela de responsabilidade, pois, de acordo com os dados revelados acima, principalmente com relação ao número de despejos por ordem judicial, é possível constatar que o Poder Judiciário tem pautado as suas decisões, muito mais pela defesa intransigente de um pretenso direito absoluto a propriedade, do que pela função social estabelecida constitucionalmente, numa situação que contribui claramente para agravar ainda mais a situação no campo.

\section{CONSIDERAÇÕES FINAIS}

Diante do que foi exposto acima, para alcançar a concretização das políticas públicas e superar o problema da inefetividade constitucional em terrae brasilis, o presente trabalho demonstrou a necessidade de enfrentar um dos maiores problemas da administração pública: a herança patrimonialista e estamental. Ao mesmo tempo, o trabalho também demonstrou a importância da atividade jurisdicional para a implementação das políticas públicas de reforma agrária, pois, diante da constitucionalização desta demanda social, o Poder Judiciario se transformou num espaço institucional importante para a concretização das conquistas democráticas do Constitucionalismo Contemporâneo.

A Constituição de 1988 é a carta política mais democrática que a sociedade brasileira construiu durante toda a República. Após diversos golpes de Estado, regimes políticos autoritários e a total ausência de liberdade política, a Constituição de 1988 foi capaz de resgatar as grandes promessas da modernidade, representadas principalmente pela igualdade, justiça social e garantia dos direitos humanos fundamentais. Assim, para alcançar a realização desse novo paradigma estatal, é necessário enfrentar o Estado patrimonialista e estamental, que impede a concretização das políticas sociais estabelecidas pela Constituição, pois, diante desse modelo estatal, a administração pública não consegue desempenhar de maneira eficiente as políticas públicas determinadas pela Constituição, já que o Estado é transformado num mero patrocinador da iniciativa privada (grandes empresas), fazendo com que o governo sempre esteja em crise quando o assunto é políticas públicas de bem-estar, mas, por outro

\footnotetext{
${ }^{40}$ A respeito da violência no campo ver os dados apresentados pela Comissão Pastoral da Terra. Disponível em: http://www.cptnacional.org.br/index.php?option=com_content\&view=article\&id=618:conflitos-no-campobrasil-2010\&catid=12: conflitos\&Itemid=94. Acessado em: 17/06/2011.
} 


\section{REVI STA ELETRÔNI CA DA FACULDADE DE DI REITO DE FRANCA \\ www.revista.direitofranca.br \\ v. 7, n.1, jul/ 2013, ISSN: 1983-4225}

lado, cada vez mais eficiente quando é obrigado a alocar recursos para "incentivar” a economia privada.

Diante de todas estas dificuldades enfrentadas pela administração pública, o Poder Judiciário surgiu como um espaço institucional importante para a materialização dos direitos recentemente constitucionalizados. Frente ao deslocamento da esfera de tensão, até então apoiada nos procedimentos políticos, para os procedimentos judiciais, o Constitucionalismo Contemporâneo passou a exigir uma posição mais intervencionista do Poder Judiciário. Em presença de um novo contexto histórico, onde o Estado Democrático de Direito amplia os direitos de setores antes marginalizados pela sociedade brasileira, é imprescindível vislumbrar uma atuação pautada pela constitucionalidade, quando o Poder Judiciário analisa casos que envolvem a questão agrária, superando uma postura tradicional que reduz a função jurisdicional a um simples exercício mecânico de silogismo jurídico. No entanto, esse novo papel constitucional do Poder Judiciário não deve ser confundido com uma atuação sem limites dos juízes, com uma postura discricionária que pode colocar em risco toda a construção democrática, pois, ao mesmo tempo em que Poder Judiciário ganhou uma maior relevância institucional no Constitucionalismo Contemporâneo, a atividade jurisdicional não pode ser encarada como a solução para as deficiências institucionais do Estado brasileiro.

Portanto, para uma verdadeira compreensão desses novos desafios, postos ao Poder Judiciário, é necessário que os juristas levem em conta a formulação de novas construções teóricas, capazes de garantir uma maior efetividade dos direitos fundamentais, pois o positivismo jurídico não é capaz de atender a complexidade dos novos problemas hodiernos, como acontece com a questão agrária, embora ainda existam alguns casos de juristas que insistem em analisar os problemas do Direito a partir desta corrente de pensamento.

Dessa forma, o Estado tem o grande desafio de realizar a reforma agrária constitucional, tão importante para a construção do regime democrático. A viabilização da reforma agrária atende aos objetivos republicanos de erradicação da pobreza e de redução substancial das desigualdades sociais. De fato, esta política pública é fundamental para a superação dos problemas sociais, pois aparece como alternativa ao alto índice de desemprego das grandes cidades e, ao mesmo tempo, permite a construção de um modelo de desenvolvimento voltado principalmente para produção de alimentos, pois no modelo atual, estabelecido há vários séculos, ainda predominam grandes propriedades monocultoras, trabalho degradante e a produção de matérias-primas voltadas essencialmente para o mercado 


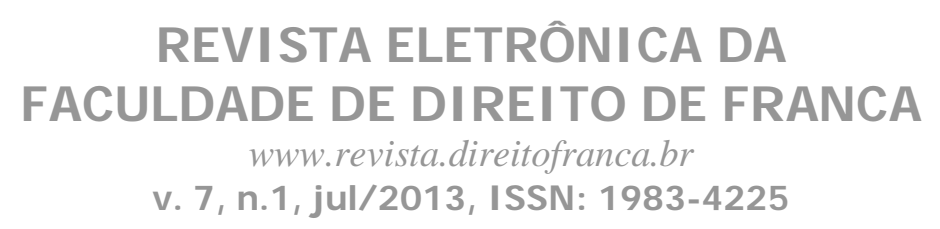

externo. Assim, para implementar as políticas públicas de reforma agrária, é necessário superar a herança patrimonialista e estamental, que impede uma atuação da administração pública compatível com o regime democrático e, ao mesmo tempo, reavaliar todo o quadro de valores tradicionais que vêm orientando a atuação jurisdicional, por meio de uma interpretação literal da lei civil, que simplesmente considera a propriedade privada da terra como um direito absoluto e que, com isso, acaba aprofundando a situação de miséria existente no campo.

\section{REFERÊNCIAS BIBLIOGRÁFICAS}

BERCOVICI, Gilberto. A problemática da constituição dirigente: algumas considerações sobre o caso brasileiro. In: Revista de Informação Legislativa n. 142. Brasília, 1999.

CAPPELLETTI, Mauro. Juízes Legisladores? Porto Alegre: Editor Sergio Antonio Fabris, 1993.

ENTERRÍA, Eduardo García de. La lengua de los derechos. La formacion del Derecho Público europeo trás la Revolución Francesa, Madrid: Alianza Editorial, 1995.

FACHIN, Luiz Edson. A justiça dos conflitos no Brasil. In: A questão Agrária e a Justiça. Juvelino José Strozake (org.). São Paulo: Editora Revista dos Tribunais, 2000.

FAORO, Raymundo. Os donos do poder: formação do patronato político brasileiro. $3^{\circ}$ ed., São Paulo: Globo, 2001.

. Democracia Traída. Coletânea de entrevistas de Raymundo Faoro. Rio de Janeiro: Globo, 2008.

FERNANDES, Florestan. Sociedade de Classe e Subdesenvolvimento, $3^{\circ}$ ed., Rio de Janeiro: Zahar Editores, 1975.

FERRAZ Jr., Tércio Sampaio. Introdução ao estudo do direito. São Paulo: Atlas, 1987.

HESSE, Konrad. Elementos de Direito Constitucional da República da Alemanha, 20a ed., Porto Alegre: Editora Sergio Antonio Fabris, 1998.

HOBSBAWM, Eric. Mundos do trabalho, 5ºd., Rio de Janeiro: Paz e Terra, 2000.

HOLANDA, Sérgio Buarque de. Raízes do Brasil. 26º ed., São Paulo: Companhia das Letras, 1995.

KELSEN, Hans. Teoria Pura do Direito. Trad. João Baptista Machado São Paulo: Martins Fontes, 1998. 


\section{REVI STA ELETRÔNI CA DA FACULDADE DE DI REITO DE FRANCA \\ www.revista.direitofranca.br \\ v. 7, n.1, jul/ 2013, ISSN: 1983-4225}

LIMA LOPES, José Reinaldo de. O Direito na História. $3^{\circ}$ ed., São Paulo: Editora Atlas, 2009.

MATEUCCI, Nicola. Organización del poder y liberdad. Historia del constitucionalismo moderno. Madrid: Trotta, 1998.

NEVES, Marcelo. Entre Têmis e Leviatã: uma relação difícil, $2^{\circ}$ ed., São Paulo: Martins Fontes, 2008.

O’DONNELL, Guillermo. Democracia delegativa? In: Novos Estudos Cebrap, n. 31, out/1991.

OLIVEIRA, Rafael Tomaz de. Decisão Judicial e o Conceito de Princípio: a hermenêutica e a (in)determinação do Direito, $1^{\circ}$ ed., Porto Alegre: Livraria do Advogado Editora, 2008.

PRADO Jr., Caio. Evolução Política do Brasil. 21ºd., São Paulo: Editora Brasiliense, 2007.

REALE, Giovanni. ANTISERI, Dario. História da Filosofia, vol. III, $5^{\circ}$ ed., São Paulo: Paulus, 1991.

SANTOS, André Leonardo Copetti. Elementos de Filosofia Constitucional. Porto Alegre: Livraria do Advogado Editora, 2009.

STEIN, Ernildo. Aproximações sobre Hermenêutica, $2^{\circ}$ ed., Porto Alegre: EDIPUCRS, 2010. STRECK, Lenio Luiz. Hermenêutica Jurídica E(m) Crise. $4^{\circ}$ ed., Porto Alegre: Livraria do Advogado, 2003.

Jurisdição Constitucional e Hermenêutica: uma nova critica do Direito, 2a ed., Rio de Janeiro: Editora Forense, 2002.

O que é isto - decido conforme minha consciência? - Porto Alegre: Livraria do Advogado Editora, 2010.

. Verdade e Consenso. $4^{\circ}$ ed., São Paulo: Saraiva, 2011.

VIANNA, Luiz Werneck; BURGOS, Marcelo Baumann; CARVALHO, Maria Alice Rezende de; MELO, Manuel Palacios Cunha. Corpo e Alma da Magistratura Brasileira, $3^{\text {a }}$ ed., Rio de Janeiro: Editora Revan, 1997.

WARAT, Luis Alberto. Introdução Geral ao Direito II. Porto Alegre: Editor Sergio Antonio Fabris, 1995.

WEBER, Max. Economia e Sociedade. Fundamentos da sociologia compreensiva. Vol. II. São Paulo: Editora UNB, 2004. 